\title{
Are apolipoproteins A and B better than lipoproteins for assessing risk of obstructive coronary heart disease?
}

\author{
Waldomiro Carlos Manfroi, Alcides José Zago, Marcelo Campos, Alexandre Alves, \\ Maria Lúcia Brisolara, Josiane de Souza, Rafael Henriques Candiago, Luciana Kirschnick, \\ Letícia Ribeiro, Kárem Ordovás, Cristiane Leitão, Rosana Cruz
}

Porto Alegre, RS - Brazil

\begin{abstract}
Objective - To evaluate whether apolipoproteins A-I (Apo A-I) and B (Apo B) have, higher ensitivity (SN), specificity $(S P)$ and positive predictive value $(P P V)$ than lipoproteins (LP), total cholesterol (TC), high density lipoprotein $(H D L)$, low density lipoprotein $(L D L)$, very low density lipoprotein (VLDL), and triglycerides (TGL) in assessing the risk of coronary heart disease (CHD).
\end{abstract}

Methods - This is a transversal case-control study of 241 patients, who were divided into two groups: 1) 145 patients with CHD, and 2) 96 patients without coronary disease. A model of logistic regression to evaluate the relation between the LPs and CHD was developed in which variables with a p-alpha $<0.1$ were included.

Results - Apo A-I levels were higher in the patients without CHD, (OR 2.08, CI 1.20-3.57). There were no statistical differences between the values of Apo A-I and the remaining lipid fractions (Apo A-I: 67\%; Apo B: 100\%; $P P V: T C=71 \% ; T G C=71 \% ; H D L=71 \% ; L D L=71 \%)$. The costs of the tests in Reais were as follows: Apo A-I: $R \$$ 56.60; Apo B-100: $R \$$ 56.60; TC: $R \$$ 9.94; HDL: $R \$ 21.30$; $L D L: R \$ 28.40 ; T G L: R \$ 14.20$.

Conclusion - Levels of Apo A-I and Apo B have no advantage over conventional lipoproteins in predicting the risk of $C H D$, despite the statistical association between Apo A-I and CHD; in addition, their costs are higher than those of the conventional lipoproteins.

Keywords: risk factors, coronary heart disease, lipoproteins

Faculdade de Medicina da Universidade Federal do Rio Grande do Sul - Porto Alegre

Mailing Address: Waldomiro Carlos Manfroi - Rua Ramiro Barcelos, 2350 - 90035 003 - Porto Alegre, RS - Brazil
One of the major scientific contributions to cardiology in the last 40 years has been the identification of risk factors for coronary heart disease (CHD). One of these risk factors, elevated serum levels of cholesterol and other lipids, plays a major role in atherogenesis and its clinical manifestations. It was demonstrated that high density lipoprotein (HDL) cholesterol acts as an attenuating agent in atherosclerosis, whereas low density lipoprotein (LDL) cholesterol acts as an accelerator of that process and of clinical instability ${ }^{1-13}$. This knowledge allowed the adoption of measurable criteria for assessment of the risk of ischemic heart disease, using serum lipoprotein levels. These systematic experiences provided clinical trials that have aimed to reduce total cholesterol (TC) and LDL, and to increase HDL with thousands of patients. These trials showed that preventive measures to reduce cholesterol, with or without medication, significantly reduced clinical events and increased the possibility of reducing the atherosclerotic plaque ${ }^{14-22}$. The encouraging results of these investigations allowed the development of more specific research on other serum proteins. Among these, the investigation of apolipoproteins A (Apo A-I) and B (Apo B) aimed to the identification of more sensitive and/or more specific parameters for the prediction of the risk of ischemic heart disease stand out ${ }^{23-60}$. The results of this research disclosed discrepancies among the different centers conducting these studies. Some studies demonstrated that only Apo B was related to CHD while others showed that only Apo A-I was. In regard to the degree of sensitivity (SN) and specificity (SP), the different results also showed discrepancies.

Based on those previous studies, we designed this study with the following aims: 1) to assess the mean value of serum apolipoproteins in our population; 2) to evaluate whether Apo A-I or Apo B levels were higher in patients with $\mathrm{CHD} ; 3$ ) to compare SN, SP and the positive predictive value (PPV) of apolipoproteins with those of other lipids; 4) 
to evaluate the applicability of measuring the apolipoproteins considering the cost-benefit ratio.

\section{Methods}

A transversal case-control study was carried out. This study comprised 308 patients with clinical and laboratory diagnosis of ischemic heart disease, who were referred to the catheterization laboratory of the Hospital das Clínicas de Porto Alegre (HCPA), from January 94 to June 96 for coronary angiography.

The patients were previously informed about the purposes of the study and also that their participation would not interfere with their treatment. Those who agreed to participate in the study signed a consent form that also authorized the withdrawal of $10 \mathrm{~mL}$ of blood for further analysis and the copy of their electrocardiogram (ECG). Then, a semistructured interview was performed, in which the risk factors and comorbidities were assessed, including the use of medication and the current status of the ischemic disease. Sixty-seven patients were excluded from the study because of the following characteristics: recent ( $<3$ months) acute myocardial infarction (AMI), use of thiadiazides in the last 2 weeks, use of lipid lowering agents, and other nonischemic heart diseases.

Cardiac catheterization was performed via the dissection of the right brachial artery or puncture of the right femoral artery, under local anesthesia ( $2 \%$ lidocaine); the selective study of the coronary arteries was performed using the techniques of Sones and Sinrey ${ }^{61}$ or Judkins ${ }^{62}$. The coronary angiographic films were analysed by two researchers who did not know about the clinical and laboratory data of the patients. This interpretation consisted of direct visualization of the pattern and degree of the obstruction, and also the number of vessels affected by the disease.

Blood was withdrawn soon after reaching the arterial lumen and subsequently analyzed in the biochemistry unit of the HCPA. TC and TGL were analyzed by the colorimetric enzymatic method, using the Autoanalyser SelectraVitaldo. HDL-cholesterol (HDL-C), LDL-cholesterol (LDLC) and VLDL-cholesterol (VLDL-C) were analyzed by the selective ionic precipitation/colorimetric enzymatic method, and Apo A-I and Apo B were analyzed by immunoturbidimetric assay and photometric measurement, with the turbiquant reagents ${ }^{63-67}$.

To calculate the SNs, SPs and PPVs of the lipids, the standard values defined by the biochemistry unit of the HCPA were used as reference values. Altered biochemical values were considered a positive test and compared with coronary angiography, which was considered the gold standard, in which at least one coronary artery with an obstruction of $50 \%$ or more represented a positive test (group with disease). For the negative tests, only the cases with no obstruction in all arteries were selected (group without disease).
The reference values of apolipoproteins used as cutpoints were recalculated in the sample with aid of a ROC curve (not shown), and the values found were similar to those standardized at the biochemistry unit of the HCPA (table I).

The univariate statistical analysis was performed with Epi-info, version 6, and the multiple linear regression and the logistic regression were performed with SPSS, version 6.01. Age, sex, obesity, smoking, hypertension, diabetes mellitus (DM), TC, HDL-C, LDL-C, TGL and APO A-I and B were included in the regression model. The statistical power of the sample was $80 \%$ and the significant p-alpha was $>0.05$. The criterion of inclusion in the logistic regression model was p-alpha $<0.1$. For the model of logistic regression, the apolipoproteins were included in quarters and then separated in the following groups: Apo A-I $<96 \mathrm{mg} / \mathrm{dL}$, between 96 and $111 \mathrm{mg} / \mathrm{dL}$, between 112 and $122 \mathrm{mg} / \mathrm{dL}$, and $>122 \mathrm{mg} /$ $\mathrm{dL}$. The same was done for Apo B and the groups were divided according to the following ranges: $<101 \mathrm{mg} / \mathrm{dL}$, between 101 and $117 \mathrm{mg} / \mathrm{dL}$, between 118 and $132 \mathrm{mg} / \mathrm{dL}$, and $>132 \mathrm{mg} / \mathrm{dL}$. The patients, divided into categories of those with and those without CHD, were then subdivided into those groups, according to their lipid profile.

\section{Results}

Of 241 selected patients, 145 had coronary atherosclerotic lesions $\geq 50 \%$, constituting the group with CHD; the remaining 96 patients constituted the group without CHD.

The male patients comprised $60 \%$ of the sample. The mean age was 61.5 and 56.7 years, respectively for the groups with and without CHD; this difference was statistically significant $(\mathrm{p}=0.0009)$. Male patients predominated in the group with CHD $(n=105)$ and females predominated in the group without CHD $(n=57)$. This presentation had a strong statistical power ( $\mathrm{p}=0.0000016)$ (fig. 1 ).

The Quetelet index also showed a significant variation in the groups with and without $\mathrm{CHD}(\mathrm{p}=0.05)$.

DM was diagnosed in 44 patients, $68.2 \%$ of whom had CHD. Hypertension was diagnosed in 125 patients, $58.4 \%$ of whom had CHD. A family history was identified in 152 patients, $57.2 \%$ of whom had CHD.

Sixty-three patients were smokers, $76.2 \%$ of whom belonged to the group with CHD (odds ratio (OR) 2.67; CI $1.33-5.44)$. Once again the male gender stood out as a risk factor for CHD(OR 3.84; CI 2.13-6.93).

\begin{tabular}{|c|c|}
\hline \multicolumn{2}{|c|}{ Table I - Reference values for cutpoints } \\
\hline Apo A-I & $<116 \mathrm{mg} / \mathrm{dL}$ \\
\hline Apo B -male & $>160 \mathrm{mg} / \mathrm{dL}$ \\
\hline female & $>150 \mathrm{mg} / \mathrm{dL}$ \\
\hline Cholesterol & $>200 \mathrm{mg} / \mathrm{dL}$ \\
\hline LDL & $>130 \mathrm{mg} / \mathrm{dL}$ \\
\hline HDL & $<35 \mathrm{mg} / \mathrm{dL}$ \\
\hline VLDL & $>30 \mathrm{mg} / \mathrm{dL}$ \\
\hline TGL ( 30 years & $>140 \mathrm{mg} / \mathrm{dL}$ \\
\hline $31-40$ years & $>150 \mathrm{mg} / \mathrm{dL}$ \\
\hline $41-50$ years & $>160 \mathrm{mg} / \mathrm{dL}$ \\
\hline$>51$ years & $>170 \mathrm{mg} / \mathrm{dL}$ \\
\hline
\end{tabular}




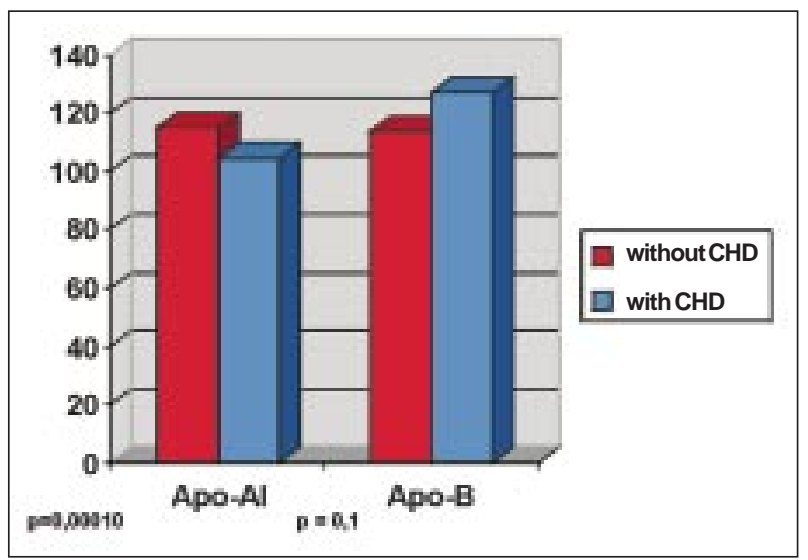

Fig. 1 - Concentration of apolipoproteins in patients with and without CHD.

The costs in Reais were as follows: Apo A-I R \$ 56.60; Apo B R \$ 56.60; TCR \$ 9.94; HDL R \$21.30; LDL R \$28.40; TGLR $\$ 14.20$.

Data showing the characteristics of the sample are presented in table II.

Apo A-I and Apo B had different behaviors in relation to the presence of coronary atherosclerosis. Serum levels of Apo B showed no significant statistical difference between the patients with and without CHD, neither by the analyses of the means nor by the laboratory reference values. Apo A-I, however, showed much lower serum levels in the group with atherosclerosis than in that without it, and the difference between these values was significant $(\mathrm{p}=0.0001)$.

In regard to TGL, TC and its lipoproteins LDL-C, HDL$\mathrm{C}$ and VLDL-C, through the analysis of variance, statistically significant differences were observed between the patients with and without CHD. Significantly greater values of cholesterol, TGL, LDL-C and VLDL-C were observed in the patients with CHD, as well as reduced levels of HDL-C. Inverted values were found in the patients without $\mathrm{CHD}$ (table III).

Comparing the serum levels of the lipids and the presence or absence of CHD in the coronary angiography, SN, SP and PPV of each lipid were calculated, and the laboratory reference values were used to classify them as normal or altered. SN of Apo A-I for the presence of CHD in this group

\begin{tabular}{|lll|}
\hline \multicolumn{3}{|c|}{ Table II - Characteristics of the sample } \\
\hline & With CHD & Without CHD \\
\hline Total of patients & 145 & 96 \\
Sex: male $(\mathrm{n}=144)^{*}$ & 105 & 39 \\
$\quad$ female $(\mathrm{n}=97)^{*}$ & 40 & 57 \\
Mean age (SD)* & $61.5(10.7)$ & $56.7(11.35)$ \\
Quetelet index (SD)* & $26.27(4.22)$ & $27.38(4.06)$ \\
Smokers (n=63) & $48(76.2 \%)$ & $15(23.8 \%)$ \\
DM (n=44) & $30(68.2 \%)$ & $14(31.8 \%)$ \\
Hypertension (n=125) & $73(58.4 \%)$ & $52(41.6 \%)$ \\
Family history of ischemic & $87(57.2 \%)$ & $65(42.8 \%)$ \\
heart disease & & \\
\hline p $<0.05$, chi-square. & \\
\hline
\end{tabular}

of patients was higher than that of the other lipid fractions with lower SP. However, its PPV did not statistically differ from the PPV of cholesterol, LDL, HDL, VLDL and TGL (table IV).

When observing Apo A-I values, one can see that, in the group without CHD, $30.5 \%$ of the patients had levels $>122 \mathrm{mg} / \mathrm{dL}$; in the group with CHD, $35.4 \%$ of the patients had levels $<96 \mathrm{mg} / \mathrm{dL}$; this association was statistically significant ( $\mathrm{p}=0.0001$ ). In regard to the values of Apo B, no significant relation with the presence of CHD was observed.

In a multivariate analysis using a model of logistic regression, where the variables sex, hypertension, DM, Quetelet index, smoking, age, and TC were controlled for, the relation proved to be significant for the levels of Apo AI $<96 \mathrm{mg} / \mathrm{dL}$ and presence of CHD with OR 2.08 (CI 1.20$3.57)$. For the patients in our study, no other relation with the presence of coronary atherosclerosis could be demonstrated in this analysis (table V).

\begin{tabular}{|c|c|c|c|}
\hline \multicolumn{4}{|c|}{ Table III - Lipid profile: mean (standard deviation) } \\
\hline & Global Mean & Without CHD & With CHD \\
\hline ApoA-1 $p=0.00001$ & $108.68(21.74)$ & $115.03(20.65)$ & $104.44(21.48)$ \\
\hline ApoB $\quad p=0.1$ & $121.58(55.8)$ & $113.53(23.8)$ & $126.94(68.95)$ \\
\hline Cholesterol $\mathrm{p}=0.009$ & $185.3(40.74)$ & $176.9(39.08)$ & $190.81(41.02)$ \\
\hline LDL-C $\mathrm{p}=0.017$ & $121.38(58.84)$ & $119.26(82.36)$ & $122.81(35.49)$ \\
\hline HDL-C ${ }^{\mathrm{p}=0.019}$ & $39.06(10.62)$ & $41.02(10.64)$ & 37.77 (10.44) \\
\hline VLDL-C ${ }^{p=0.015}$ & $28.13(14.71)$ & $24.48(14.42)$ & 30.57 (14.44) \\
\hline TGL $^{p=0.0002}$ & $142.82(84.77)$ & $128.01(97.62)$ & $152.63(73.81)$ \\
\hline
\end{tabular}

\begin{tabular}{|c|c|c|c|}
\hline \multicolumn{4}{|c|}{$\begin{array}{l}\text { Table IV - Sensitivity, specificity and positive predictive } \\
\text { values for lipids }\end{array}$} \\
\hline Value & Sensitivity & Specificity & PPV \\
\hline ApoA-1 & $66 \%$ & $51 \%$ & $66 \%$ \\
\hline ApoA-1 male & $64 \%$ & $42 \%$ & $73 \%$ \\
\hline ApoA-1 female & $68 \%$ & $57 \%$ & $55 \%$ \\
\hline Apo B & $06 \%$ & $99 \%$ & $90 \%$ \\
\hline Cholesterol & $41 \%$ & $75 \%$ & $71 \%$ \\
\hline LDL & $37 \%$ & $76 \%$ & $70 \%$ \\
\hline HDL & $48 \%$ & $66 \%$ & $68 \%$ \\
\hline VLDL & $42 \%$ & $69 \%$ & $67 \%$ \\
\hline TGL & $27 \%$ & $83 \%$ & $71 \%$ \\
\hline
\end{tabular}

\begin{tabular}{|ccccc|}
\hline \multicolumn{5}{|c|}{ Table V - Apo A-I and Apo B levels and the presence of CHD } \\
\hline Apo A-I $\mathrm{p}=0.0001$ & Without CHD & With CHD & OR* & CI $(95 \%)^{*}$ \\
$>122 \mathrm{mg} / \mathrm{dL}$ & $29(30.5 \%)$ & $22(15.3 \%)$ & 1 & \\
$112-122 \mathrm{mg} / \mathrm{dL}$ & $26(27.3 \%)$ & $32(22.2 \%)$ & 0.81 & $0.48-1.37$ \\
$96-111 \mathrm{mg} / \mathrm{dL}$ & $25(26.4 \%)$ & $39(27.1 \%)$ & 1.03 & $0.60-1.75$ \\
$<96 \mathrm{mg} / \mathrm{dL}$ & $15(15.8 \%)$ & $51(35.4 \%)$ & 2.08 & $1.20-3.57$ \\
Apo-B ${ }^{\mathrm{p}=0.27}$ & & & & \\
$<101 \mathrm{mg} / \mathrm{dL}$ & $29(30.2 \%)$ & $38(26.2 \%)$ & 1 & \\
$101-117 \mathrm{mg} / \mathrm{dL}$ & $21(21.8 \%)$ & $35(24.1 \%)$ & 1.06 & $0.62-1.86$ \\
$118-132 \mathrm{mg} / \mathrm{dL}$ & $33(34.4 \%)$ & $38(26.2 \%)$ & 0.52 & $0.97-3.78$ \\
$>132 \mathrm{mg} / \mathrm{dL}$ & $13(13.3 \%)$ & $34(23.5 \%)$ & 1.71 & $0.87-3.39$ \\
\hline \multirow{5}{*}{ Multivariate analysis. } & & & \\
\hline
\end{tabular}


The SNs, SPs and PPVs of the lipids for the presence or absence of CHD varied according to the age of the patients. The measurement of Apo A-I had its peak of SN for $\mathrm{CHD}$ in the patients under 50 years of age and its higher SP in the age range from 50 to 59 years. TC showed a distribution similar to that of Apo A-I in these patients. PPVs in the patients over 50 years of age were equivalent (table VI).

\section{Discussion}

Even though the alterations in the metabolism of the TC, TGL, HDL, LDL, and VLDL are already well established risk factors for CHD, other lipid fractions were studied in an attempt to identify other more reliable biochemical parameters that can be universally employed to stratify the risk of CHD. These parameters should have reliable results with a small margin of error, be more economical or have better SN and SP than the dosages already well established. Among the new lipid fractions that have been studied, the studies with Apo A-I and Apo B stand out.

Our studies showed that the lipid profile as well as the other risk factors were similar to the Framingham studies ${ }^{1,3,4}$. Apolipoproteins levels were equivalent to those of other populations studied. In regard to the presence of CHD, using adequate statistical methods, we observed that the patients with CHD have lower levels of Apo A-I; Apo B levels were not statistically different from patients without CHD.

Sedlis et $\mathrm{al}^{41}$, when relating CHD and apolipoproteins, found that the ratio Apo A-I/Apo B explains better the variation of CHD prevalence than the ratio LDL/HDL. However, when they compared the levels of Apo A-I in patients with and without CHD, no significance was found. The methodology they employed, however, was different from that employed in our study; in their study, patients with $\mathrm{CHD}$ were those whose score was $\geq 1$, i.e., patients with $25 \%$ or more of obstruction in at least one artery, and without CHD those with 0 to $24 \%$ of obstruction, who scored no point. This may explain the differences found, because our study classified, as CHD, only patients with a

\begin{tabular}{|cccc|}
\hline \multicolumn{2}{|c|}{ Table VI - Sensitivity, specificity and PPV according to age } \\
\hline Age & Sensitivity & Specificity & PPV \\
\hline$<50$ years & & & \\
Apo A-I & $70 \%$ & $30 \%$ & 50 \\
Cholesterol & $45 \%$ & $55 \%$ & 64 \\
$50-59$ years & & & \\
Apo A-I & $62 \%$ & $38 \%$ & 69 \\
Cholesterol & $38 \%$ & $62 \%$ & 72 \\
$60-69$ years & & & \\
Apo A-I & $68 \%$ & $32 \%$ & 73 \\
Cholesterol & $41 \%$ & $59 \%$ & 72 \\
$>69$ years & & & \\
Apo A-I & $65 \%$ & $35 \%$ & 71 \\
Cholesterol & $44 \%$ & $56 \%$ & 75 \\
\hline
\end{tabular}

stenosis of $50 \%$ or more in at least one artery, and without CHD those who had no obstruction at all.

Kwiterovich et $\mathrm{al}^{54}$, who analyzed the relation between Apo A-I and premature CHD, found an association between Apo A-I and CHD in men, as well as between Apo B and $\mathrm{CHD}$ in women and the ratio Apo A-I/Apo B with significance for both sexes, but without any relation with isolated Apo A-I. Those authors defined as CHD the presence of stenosis greater than $50 \%$ in at least one artery and as absence of CHD those lesions ranging from 0 to $49 \%$; once more, this may account for the differences with our study.

Fujiwara et al ${ }^{57}$ compared CHD identified by coronary angiography with serum levels of apolipoproteins, lipids and insulin in nondiabetic patients. Based on 42 patients, they found that levels of Apo A-I and Apo B are the best lipid fractions to differentiate patients with and without CHD. In regard to Apo A-I, the results were similar to ours, even though they considered patients with CHD those with obstruction of more than $75 \%$ in at least one artery and patients without CHD those with an arterial stenosis of up to $25 \%$.

Other studies analyzed the relation between the apolipoproteins and AMI. In a prospective study with an 8.6year duration, Sigurdsson et $\mathrm{al}^{55}$ analyzed the risk of AMI in different levels of Apo A-I and Apo B and other lipid fractions, and concluded that Apo A-I in men had a PPV, same risk as HDL, and the association of Apo B was not statistically significant. Even though this study did not use anatomical findings, its results were comparable to ours. Rubin et al $^{53}$, in an experimental study, showed that the higher levels of Apo A had no relation with the event AMI. In another study, Sewardsen et $\mathrm{al}^{47}$ found an association demonstrating that Apo B was a better marker of CHD than the other lipid fractions, but they only analyzed normocholesterolemic nondiabetic Indian men. Analyzing the plasma from 246 patients with and without AMI, withdrawn 5 years prior to the event, Stampfer et $\mathrm{al}^{49}$ found a relation between the high levels of Apo B, as a risk factor, and Apo A-I, as a factor for protection against AMI; in the multivariate analysis, this significance was lost. Kuyl and Mendelson ${ }^{56}$, in an observational study, found no difference between the distribution of the ratios HDL/cholesterol and Apo A-I/Apo $\mathrm{B}$, concluding that it added nothing to the dosage of these lipid fractions.

The analysis of SN, SP and PPV of the apolipoprotein and the other lipoproteins in our study shows that, even though Apo A-I had a higher SN than TC and LDL, its SP was lower and the PPV is similar. In regard to the HDL fraction, Apo A-I has a higher SN, lower SP and the same PPV. In regard to VLDL, it had a higher SN, same SP and same PPV. In regard to TGL, Apo A-I had a higher SN, a lower SP and a similar PPV (table III). Considering the prices of the exams, the costs in Reais were as follows: Apo A-I cost ranged from $\mathrm{R} \$ 30.0$ to $\mathrm{R} \$ 56.80$; HDL cost ranged from $\mathrm{R} \$ 21.30$ to $\mathrm{R} \$ 48.00$; and the TC cost ranged from $\mathrm{R} \$ 8.40$ to $\mathrm{R} \$ 9.94$. 
Considering the small advantage of Apo A-I compared to TC in regard to SN, SP and PPV and its high cost, we found no advantage in using Apo A-I as a factor of identification of risk for coronary atherosclerosis. Considering the other lipoproteins, Apo A-I could replace the HDL, LDL and VLDL fractions because of its higher SN and similar costs.

Based on the methodology employed in this study and considering its limitations, we can conclude the follo- wing: 1) the levels of Apo A-I and Apo B in the population of Porto Alegre are equivalent to the levels identified in other populations; 2) patients with obstructive coronary heart disease have lower serum levels of Apo A-I than those with no coronary artery disease; 3 ) the measurement of the levels of Apo A-I do not replace those already well established tests for the stratification of the coronary risk and its cost is higher; 4) serum levels of Apo B did not differ in the groups with and without coronary heart disease.

\section{References}

1. The Framingham Study. An epidemiological investigation of cardiovascular disease. Some characteristics related to the incidence of cardiovascular disease and death: 16-year follow-up. Monograph section 26, US Government Printing Office, 1973 .

2. Margolis Jr, Gillum Rf, Feinlib M, et al. Community surveillance for coronary heart disease: the Framingham Cardiovascular Disease Survey. Methods and preliminary results. Am J Epidemiol 1974; 100: 425-36.

3. Kannel WB, McGee D, Gordon T. A general cardiovascular risk profile: The Framingham Study. Am J Cardiol 1976; 38: 46-51.

4. Margolis JR, Gillum RF, Feinlib M, Brasch R, Fabsitz R. Community surveillance for coronary heart disease: The Framingham Cardiovascular Disease Survey. Am J Cardiol 1976; 37: 61-7.

5. Gordon T, Castelli WP, Hortland MC, Kannel WB, Danber TR. High-density lipoprotein as a protective factor against coronary artery disease: The Framingham Heart Study. Am J Med 1977; 62: 707-14

6. Wilson PW, Garrison RJ, Castelli WP, Feinlib M. Prevalence of coronary heart disease in the Framingham offspring study: role of lipoprotein cholesterol. Am J Cardiol 1980; 46: 649-54

7. Whayne TF, Alaupovic P, Curry MD, Lee ET, Anderson OS, Schechter E. Plasma apolipoprotein B and VLDL and HDL cholesterol as risk factors in the development of coronary artery disease in male patients examined by angiography. Atherosclerosis 1981; 39: 411-24.

8. Manfroi WC, Marques G, Goldim JR, et al. Correlação entre a aterosclerose coronária e a dislipidemia. Arq Bras Cardiol 1982; 39: 15-19.

9. Castelli WP, Abbott RD, McNamora PM. Summary estimates of cholesterol used to predict coronary heart disease. Circulation 1983; 67: 730-4

10. Assman G, Schulte H. The Prospective Cardiovascular Müster (PROCAM) study: Prevalence of hyperlipidemia in persons with hypertension and/or diabetes mellitus and the relationship to coronary heart disease. Am Heart J 1988; 116: 1713-24

11. Levy D, Wilson PWF, Anderson KM, et al. Stratifying the patient at risk for coronary disease. New insights from the Framingham Heart Study. Am Heart J 1990; 119: 712-7.

12. Klag MJ, Ford DE, Mead LA, et al. Serum cholesterol in young man and subsequent cardiovascular disease. N Engl J Med 1993; 328: 313-18.

13. Schultz JR, Verstuyft JG, Gong EL, Nichols AV, Rubin EM. Protein composition determines the anti-atherogenic properties of HDL in transgenic mice. Nature 1993, 365: 762-4.

14. Report of the National Cholesterol Education Program Expert Panel on detection, evaluation, and treatment of high blood cholesterol in adults. Arch Intern Med 1988, 148: 36-69.

15. Brett AS. Treating hypercholesterolemia: how should the practicing physicians interpret the published data for patients? N Engl J Med 1989; 321: 676-9.

16. Scandinavian Simvastatin Study Group - Randomized Trial of cholesterol lowering in 4444 patients with coronary artery disease: the Scandinavian Simvastatin Survival Group (4S). Lancet 1994; 344: 1383-9.

17. Byington RP, Jukema JW, Salonen JT, et al. Reduction in cardiovascular events during pravastatin treatment. Circulation 1995; 92: 2419-25.

18. Shepherd J, Cobble SM, Ford I, et al. Prevention of coronary heart disease with pravastatin in men with hypercholesterolemia. West of Scotland Prevention Study Group. N Engl J Med 1995; 333: 1301-7.

19. Pitt B, Mancini GBJ, Ellis S, et al. Pravastatin Limitation of Atherosclerosis in the Coronary Arteries (PLAC I): Reduction in Atherosclerosis Progression and Clinical Events. J Am Coll Cardiol 1995; 26: 1133-9.
20. Jukema JW, Bruschke AVG, van Boven AJ, et al. Effects of lipid lowering by pravastatin on progression and regression of coronary artery disease in symptomatic men with normal to moderately elevated serum cholesterol levels: the Regression Growth Evaluation Statin Study(Regress). Circulation 1995; 91: 2528-40

21. Sacks FM,Pfeffer MA, Moye LA, et al. The effect of pravastatin on coronary events after myocardial infarction in patients with average cholesterol levels. N Engl J Med 1996; 335: 1001-09.

22. Andrews TC, Raby K, Barry J, et al. Effect of cholesterol reduction on myocardial ischemia in patients with coronary disease. Circulation 1997; 95: 324-8.

23. Avogaro P, Bittolo Bon G, Cazzolato G, et al. Variations in apolipoproteins B and A-I during the course of myocardial infarction. Eur J Clin Invest 1978; 8: 121-9.

24. Avogaro P, Cazzolato G, Bittolo Bon G, Oninci GB. Are apolipoproteins better discriminators than lipids for atherosclerosis? Lancet 1979; 1: 901-03.

25. Avogaro P, Bittolo Bon G, Cazzolato G, Rorai E. Relationship between apolipoproteins and chemical components of lipoproteins in survivors of myocardial infarction. Atherosclerosis 1980; 37: 69-76.

26. Fazer G, Wiklund O, Olafsson S-O, Wilhelmsson C, Bondjeus G. Serum apolipoprotein levels in relation to acute myocardial infarction and its risk factors. Atherosclerosis 1980; 36: 67-74

27. Riesen WF, Mordosini R, Salzmann C, Theles A, Gurtner HP. Apolipoprotein and lipids as discriminator of severity of coronary heart disease. Atherosclerosis 1980; 37: 157-62.

28. Deslypere JP, DeBaker G, Rosseneu M, Vermnelen A. Lipids and apoprotein levels in myocardial infarction survivors: a case-control study. Acta Cardiol 1981; 27(suppl): 92.

29. De Baker G, Rosseneu M, Deslypere JP. Discriminative value of lipid and apolipoproteins in coronary heart disease. Atherosclerosis 1982; 42: 197-203.

30. Maciejko JJ, Heines DR, Kottke BA, Zinsmeister AR, Dihn DM, Mao SJ Apolipoprotein A-I as a marker of angiographically assessed coronary artery disease. N Engl J Med 1983; 309: 385-9.

31. Noma A, Yokosuka T, Kitamura K. Plasma lipids and apolipoproteins as discriminators for presence and severity of angiographically defined coronary artery disease. Atherosclerosis 1983; 49: 1-7.

32. Kukito H, Hiwada K, Kakubo T. Serum apolipoproteins A-I, A-II and B levels and their discriminative values in relatives of patients with coronary artery disease. Atherosclerosis 1984; 51: 261-7.

33. Brunzell JD, Sniderman AD, Albers JJ, Kwiterovich PO. Apoprotein B and A-I and coronary artery disease in humans. Atherosclerosis 1984; 4: 49-83.

34. Scmidt SB, Wassermann AG, Muesing RA, Schlesselman SE, Lorosa JC, Ross AM. Lipoprotein and apolipoprotein levels in angiographically defined coronary atherosclerosis. Am J Cardiol 1985; 55: 1459-62.

35. Kukita H, Hamada M, Hiwada K, Kokubu T. Clinical significance of measuremen of serum apolipoproteins AI, AII and B in hypertriglyceridaemic male patients with and without coronary artery disease. Atherosclerosis 1985; 55: 143-9.

36. Naito HK. The association of serum lipids, lipoproteins and apolipoproteins with coronary artery disease assessed by coronary arteriography. Ann NY Acad Sci $1985 ; 454: 230-8$

37. Durrington PN, Hunt L, Ishola M, Kane J, Stephens WP. Serum apolipoprotein $\mathrm{AI}$ and $\mathrm{B}$ and lipoproteins in middle aged men with and without previous myocardial infarction. Br Heart J 1986; 56: 206-12.

38. KottkeBA,Zinsmeister AR, Holmes DR, Kneller RW, Hallaway BJ, Mao SJT. Apolipoproteins and coronary artery disease. Mayo Clin Proc 1986; 61: 313-20. 
39. Hamsten A, Walldius G, Stamosi A, Dohlen G, de Faire U. Relationship of angiographically defined coronary artery disease to serum lipoproteins and apolipoproteins in young survivors of myocardial infarction. Circulation 1986; 73: 1097-110.

40. Aro A, Soimakallio S, Vontilainen E, Ehnholm C, Wiljasalo M. Serum lipoprotein lipid and apoprotein levels as indicators of the severity of angiographically assessed coronary artery disease. Atherosclerosis 1986; 62: 219-25.

41. Sedlis SP, Schechtman KB, Ludbrook PA, Sobel BE, Schonfeld G. Plasma apolipoproteins and the severity of coronary artery disease. Circulation 1986; 73: $978-86$.

42. Miller NE. Associations of high-density lipoprotein subclasses and apolipoproteins with ischemic heart disease and coronary atherosclerosis. Am Heart J 1987; 113: 589-97.

43. Durrington PN, Hurt L, Ishda M, Arrol S, Bhatnagar D. Apolipoproteins (a), AI and $\mathrm{B}$ and parental history in men with early onset ischaemic heart disease. Lancet 1988; i: 1070-3.

44. Borbir M, Wile D, Trayner I, Arber VR, Thompson GR. High prevalence of hypertriglyceridaemia and apolipoprotein abnormalities in coronary artery disease. Br Heart J 1988; 60: 397-403.

45. Von Stiphout WAHJ, Hofman A, Kruijssen HACM, Vermeeren R, Groot PHE. Is the ratio of Apo-B/apo A-I an early predictor of coronary atherosclerosis? Atherosclerosis 1989; 62: 179-82

46. Reinhart RA, Goni K, Arndt MR, Broste SK. Apolipoproteins A-I and B as predictors of angiographically defined coronary artery disease. Arch Intern Med 1990; 150: 1629-33.

47. Sewdarsen M, Desai RK, Vythilingum S, Shah N, Rajput MC. Serum lipoproteins and apolipoproteins in young normocholesterolaemic, non-diabetic Indian men with myocardial infarction. Postgrad Med J 1991; 67: 159-64.

48. Bhatnagar D, Durrington PN. Clinical value of apolipoprotein measurement. Ann Clin Biochem 1991; 28: 427-37.

49. Stampfer MJ, Sacks FM, Salvini S, Willet WC, Hennekeus CH. A prospective study of cholesterol, apolipoproteins and risk of myocardial infarction. N Engl J Med 1991; 325: 373-81.

50. Pan QX, Liu P, Wang SC, et al. The study of serum apoprotein levels as indicators for the severity of angiographically assessed coronary artery disease. Am J Clin Pathol 1991.

51. Tornvall P, Korpe F, Carlson LA, Hamsten A. Relationships of low density lipoprotein subfractions to angiographically defined coronary artery disease in young survivors of myocardial infarction. Atherosclerosis 1991; 90: 67-8095: 597-600.

52. Pollak H, Arnolder O, Enenkel, Fischer M, Trubert-Exinger D. Apolipoprotein $\mathrm{A}$ and prognosis after myocardial infarction in non-diabetic men. Klin Wochenschr 1991; 69: 10-15
53. Rubin EM, Krauss RM, Spongler EA, Verstuyft JG, Clift SM. Inhibition of early atherogenesis in transgenic mice by human apolipoprotein AI. Nature 1991; 353: 265-7.

54. Kwiterovich Jr PO, Coresh J, Smith HH, Bachorik OS, Derby CA, Pearson TA Comparison of the plasma levels of apolipoproteins B and A-I, and other risk factors in men and women with premature coronary artery disease. Am J Cardiol 1992; 69: 1015-21.

55. Sigurdsson G, Baldursdottir A, Sigurdsson H, Agnorsson M, Thorgeirsson G, Sigfusson N. Predictive value of apolipoproteins in a prospective survey of coronary artery disease in men. Am J Cardiol 1992; 69: 1251: 4.

56. Kuyl JL, Mendelson D. Observed relationship between ratios HDL-cholesterol/total cholesterol and apolipoprotein A-I/apolipoprotein B. Clin Biochem 1992; 25: 313-16.

57. Fujiwara R, Kutsumi Y, Hayoshi T, et al. Relation of angiographically defined coronary artery disease and plasma concentrations of insulin, lipid, and apolipoprotein in normolipidemic subjects with varying degrees of glucose tolerance. Am J Cardiol 1995; 75: 122-6.

58. 2-Atger V, Giral P, Simon A, et al, PCV METRA Group. High density lipoprotein subfractions as markers of early atherosclerosis. Am J Cardiol 1995; 75: 127-31.

59. Krauss RM. Dense low density lipoproteins and coronary artery disease. Am J Cardiol 1995; 75: 53B-57B.

60. Lamarche B, Moorjani S, Lupien PJ, et al. Apolipoprotein A-I and B levels and the risk of ischemic heart disease during a five-year follow-up of men in Québec. Cardiovascular Study. Circulation 1996; 94: 3: 273-8.

61. Sones FJ, Sinrey EK. Coronary arteriography. Mod Concepts Cardiovasc Dis 1962; 31: 735-8.

62. Judkins MF. Selective coronary arteriography: a percutaneous transfemoral technique. Radiology 1967; 89: 815-24.

63. Levinson SS, Wagner SG. Measurement of apolipoprotein B-containing lipoproteins for routine clinical laboratory use in cardiovascular disease. Arch Pathol Lab Med 1992; 116: 1350-4.

64. Brustolin D, Maierna M, Aguzzi F, et al. Immunoturbidimetric method for routine determinations of apolipoproteins A-I and B. Clin Chem 1991; 37: 742-7.

65. Marcovia SM, Albero JJ, Dati F, Ledue TB, Ritchie RF. International federation of clinical chemistry standardization project for measurements of apolipoproteins A-I and B. Clin Chem 1991; 37: 1676-82.

66. Cooper GR, Henderson LO, Smith SJ, Hannon WH. Clinical applications and standardization of apolipoprotein measurements in the diagnostic workup of lipid disorders. Clin Chem 1991; 37: 619-20.

67. Rostogi A, Bren ND, Hallaway BJ, Kottke BA. Immunomagnetic separation of subpopulations of apolipoprotein A-I. Mayo Clin Proc 1994; 69: 137-43. 